\title{
Fray Servando Teresa de Mier, José Cadalso oder die Schärfe neuspanischer wie spanischer Blickwechsel
}

Es kann keinen Zweifel daran geben, dass der nun vorzustellende und zu besprechende neuspanische beziehungsweise mexikanische Dominikanermönch Fray Servando José Teresa de Mier Noriega y Guerra, der an einem 18. Oktober 1765 in Monterrey das Licht der Welt erblickte, ein wichtiger Teil jenes Disputs um die Neue Welt war, dem wir ausführlich in dieser Vorlesung unsere Aufmerksamkeit gewidmet haben. Diese Tatsache sowie wie Wendung Miers an eine vorwiegend neuspanische und amerikanische Leserschaft wird in seinen Schriften auf Schritt und Tritt deutlich. So erwähnte er beispielsweise in einer seiner Schriften, wenn auch mehr als „anécdota“1, einen lügnerischen Reisebericht über Amerika, der vor allem aus finanziellen Motiven geschrieben worden sei, den er aber für repräsentativ bezüglich all der Lügen hielt, die in Europa über Amerika und die Amerikaner verbreitet würden.

Gegen solche zum Teil dreiste Lügen wandte sich der Dominikaner energisch. Beim europäischen Publikum schien jedoch eine große Nachfrage nach solchen Reiseberichten zu herrschen, welche die dominierenden Stereotypen über Amerika bestätigten. Mier schildert nun, wie er gegen diesen ,Reisebericht‘, den ursprünglich französischen Viajero Universal, anzuschreiben und zu polemisieren versuchte, was jedoch vergeblich geblieben sei:

Ich schrieb an Tres Palacios und beklagte mich über die Blasphemien, welche der Viajero gegen den verehrenswerten Bischof Casas veröffentlichte, und dass er bezüglich der Geographie Amerikas absolut ignorant war. Tres Palacios schickte diesen Brief an Estala und sagte ihm, dass wir Mexikaner allesamt so seien und dass er uns dieses Geschäft schwermachen solle. Daraufhin kopierte Estala gegen Amerika und speziell gegen Mexiko alle Absurditäten und Ungereimtheiten von de Pauw und seinen Nachfolgern Raynal, Robertson und Laharpe, so als ob deren Argumente nicht längst von Valverde, Carli, Clavijero, Molina, Iturri, Madison und vielen mehr in Staub aufgelöst worden wären. [...]

So verlaufen alle Dinge in Spanien. Ich begann, gegen den Viajero zu schreiben und um in die Zeitung die Cartas de Tulitas Cacaloxochitl Cihuapiltzin Mexica, eines mexikanischen Fräuleins, gegen den Viajero Universal zu setzen. [...] Doch der Viajero wurde ins Portugiesische übersetzt und diente später als Leitschnur für die englische Geographie

1 Mier, Fray Servando Teresa de: Memorias. Edición y prólogo de Antonio Castro Leal. México: Editorial Porrúa 1946, Bd. 2, S. 186.

Ә Open Access. (C) 2021 Ottmar Ette, publiziert von De Gruyter. (c) BY-NC-ND Dieses Werk ist lizenziert unter einer Creative Commons Namensnennung - Nicht-kommerziell - Keine Bearbeitung 4.0 International Lizenz. https://doi.org/10.1515/9783110703467-015 
von Guthrie, der zudem allen Unsinn von Estala gegen Mexiko abschrieb. So finden die Beleidigungen und die Irrtümer kein Ende. ${ }^{2}$

Fray Servando Teresa de Mier lässt keinen Zweifel daran, dass derartige Publikationen in Europa noch immer Teil jener Polemik europäischer Aufklärer gegen die amerikanischen Kolonien waren und trotz aller erfolgreichen Gegenargumente gegen die Schriften von de Pauw, Robertson oder Raynal noch immer in Europa und insbesondere in Spanien massiv zirkulierten. Wir können dies vor dem Hintergrund unserer Vorlesung, mit Blick auf Kant oder Hegel auch für die deutsche Philosophie grosso modo bestätigen. Denn diese Ansichten blieben in Europa populär und der Absatz derartiger vorurteilsbeladener Schriften und ,Reiseführer hoch.

Beim Viajero universal handelt es sich um eine gesamteuropäische, aus kommerziellen Gründen entstandene und mit verbreiteten europäischen Vorurteilen spielende, verzerrende Darstellung Amerikas, die nicht die Darstellungen etwa der neuspanischen Aufklärung, sondern europäischer Autoren berücksichtigten. Wir hatten freilich gesehen, dass die aufklärerischen europäischen „Abbés“ wie Cornelius de Pauw, Guillaume-Thomas Raynal oder William Robertson niemals nach Amerika gereist waren; dennoch wurden ihre Ansichten in einen Reiseführer über die Amerikas aufgenommen. Dem stellte sich der neuspanische Mönch, der ebenfalls dem niederen Klerus zuzurechnen war, mit allem Nachdruck entgegen.

In Europa blieben diese Bemühungen Miers freilich ohne größeren Erfolg. Denn die - wie wir im Zeitalter Donald Trumps sagen könnten - alternativen Fakten europäischer Philosophen zählten weit mehr und wurden erst mit dem von Alexander von Humboldt mitbewirkten Paradigmenwechsel kurz nach der Wende zum 19. Jahrhundert auch in Europa zumindest im Bereich der Wissenschaft in Frage gestellt. ${ }^{3}$ Fraglos lässt sich Fray Servandos wiederholte Darstellung Europas in Form eines Reiseberichtes aus der Perspektive eines Amerikaners als der gelungene Versuch eines Gegenentwurfs, vielleicht gar - denken wir an den emotionalen Grundton wie den oft vehementen Stil seiner Memoiren, an die „vehemencia natural de mi estilo“4 und an seine „einfordernde amerikanische Wut“ ${ }^{5}$ als eine

2 Mier, Servando Teresa de: Memorias, Bd. 2, S. 187.

3 Vgl. Ette, Ottmar: Réflexions européennes sur deux phases de mondialisation accélérée chez Cornelius de Pauw, Georg Forster, Guillaume-Thomas Raynal et Alexandre de Humboldt. In: HiN - Alexander von Humboldt im Netz. Internationale Zeitschrift für Humboldt-Studien (Potsdam - Berlin) XI, 21 (2010), S. 1-28 (http://www.hin-online.de).

4 Mier, Fray Servando Teresa de: Memorias, Bd. 1, S. 234.

5 Calvillo, Manuel: Nota previa. In: Mier, Fray Servando Teresa de: Cartas de un americano, 1811-12. Nota previa de Manuel Cavillo. Mexiko: Partido Revolucionario Institucional 1976, S. lviii: ,ira americana reivindicadora.“ 
Art literarischer Rache an den europäischen Verballhornungen verstehen. Fray Servando bediente sich dabei der ,Methode von de Pauw` und hob gerade die skurrilen und absurden Seiten der von ihm besuchten europäischen Länder fest. Eine größere Wirkung seiner Schriften auf die Zeitgenossen in Europa lässt sich freilich in keiner Weise beobachten.

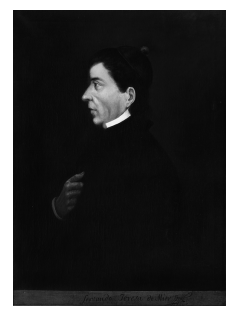

Abb. 39: Servando Teresa de Mier (1763-1827).

Doch wie kam es überhaupt dazu, dass der neuspanische Kleriker über Europa berichten konnte? War er von seinem Orden ausgeschickt worden? Hatte ihn irgend ein amerikanisches Periodikum in die Alte Welt entsandt? Oder war er selbst, vergleichbar mit einem Alexander von Humboldt, auf eigene Kosten aufgebrochen, um eine Forschungsreise quer durch die damaligen Staaten Europas anzutreten und seinen Landsleuten von dieser Reise zu berichten? Nichts von alledem ist zutreffend. Denn die Reisen Fray Servandos waren alles andere als freiwillig.

Zunächst einmal dürfen wir festhalten, dass Fray Servando keinen eigentlichen Reisebericht veröffentlichte, sondern sich der Gattung der Autobiographie im Sinne Rousseaus bediente, auch wenn er noch immer - und fälschlich - die Gattungsbezeichnung Memoiren wählte. Doch er war kein berühmter Fürst oder hoher Kirchenmann, kein Vizekönig oder Staatsmann, sondern ein einfacher Kleriker, der seine eigene Lebensgeschichte im Lichte moderner Subjektivität mit Hilfe einer Reihe literarischer Verfahren entfaltete, auf die wir mit Blick auf das 19. Jahrhundert bereits in unserer Vorlesung über das Zeitalter einer Romantik zwischen zwei Welten ausführlich gekommen waren. ${ }^{6}$ Ich möchte mich daher an dieser Stelle auf jene Aspekte konzentrieren, die den 1765 geborenen im Lichte des Zeitalters der Aufklärung zeigen und weniger seine aktive Rolle beleuchten, die er im Kampf um die „Independencia“ Neuspaniens und der spanischen Kolonien in Amerika im 19. Jahrhundert spielen sollte.

Fray Servando Teresa de Mier wurde weltweit durch den großartigen Roman des kubanischen Romanciers Reinaldo Arenas berühmt, der in El mundo aluci-

6 Vgl. das Fray Servando und Simón Bolívar gewidmete Kapitel in Ette, Ottmar: Romantik zwischen zwei Welten, S. 335-382. 
nante den mexikanischen Mönch und dessen Memoiren folgt. Servandos Texte werden zum Ausgangspunkt einer literarisch gekonnt dargestellten Verfolgungsjagd durch die verschiedensten Gebiete Neuspaniens, Amerikas und Europas. Der junge Arenas hatte freilich gut bei seinem literarischen Meister aufgepasst und zugehört. Denn die Wiederentdeckung von Fray Servando Teresa de Mier ist zweifellos ein wesentliches Verdienst des kubanischen Dichters, Essayisten und Romanciers José Lezama Lima, der den Dominikaner zurecht zwischen Barock und Romantik situierte.

Wir dürfen allerdings hinzufügen, dass Fray Servando selbstverständlich ein genuiner Bestandteil der neuspanischen Aufklärung war, deren Konturen Lezama freilich weniger interessierten als Barock und Romantik. In seinem archipelartig aufgebauten Essayband La expresión americana, mit dem wir uns bereits in unserer Vorlesung zu den Literaturen des 20. Jahrhunderts beschäftigt haben, ${ }^{7}$ hatte der Autor von Paradiso das persönliche, literarische und politische Schicksal des Mexikaners Revue passieren lassen und kam in seinem Kapitel „El romanticismo y el hecho americano“ zu folgender Einschätzung:

Bei ihm geht die religiöse Verfolgung in die politische Verfolgung über, und als er in London ist und Nachrichten vom Aufstand eines Pfarrers namens Hidalgo erhält, verfasst er sogleich Flugschriften, welche die separatistischen Einstellungen rechtfertigen. Er streift um die Kerker und nähert sich freundschaftlich dem Liberalismus von Jovellanos an, kämpft gegen die französische Invasion oder geht mit den Verschwörern von Mina an Land: Am Ende findet er mit der Proklamation der Unabhängigkeit seines Landes die Fülle seiner Rebellion und jene Form, welche seine Reife brauchte, damit sein Leben schließlich den Sinn seiner historischen Projektion zu erreichen vermochte.

In Fray Servando, in diesem Übergang vom Barock zur Romantik, überraschen wir verborgene und höchst amerikanische Überraschungen. Er glaubt mit der Tradition zu brechen, wo er sie doch erweitert. So trifft er, wenn er sich vom Spanischen zu trennen glaubt, doch wieder darauf, nur erweitert. ${ }^{8}$

Der Kubaner José Lezama Lima weist in seinen Ausführungen zum einen darauf hin, wie die persönlich bedingte Rebellion des Protomexikaners Fray Servando, die aus bestimmten gesellschaftlichen, religiösen und individuellen Bedingungen erwächst, in die politische Revolte und Revolution einfließt, ja spektakulär umschlägt. Zum anderen ordnet er den Dominikanermönch einer Zwischenstellung zu, die vom kolonialspanischen Barock zur amerikanischen Romantik hinüberleitet, welche hier unverkennbar als eine „Romantik zwischen zwei Welten“ verstanden und selbstbe-

7 Vgl. hierzu das Kapitel in Ette, Ottmar: Von den historischen Avantgarden bis nach der Postmoderne, S. $745 \mathrm{ff}$.

8 Lezama Lima, José: La expresión americana. Madrid: Alianza Editorial 1969, S. 91. 
wusst als „expresión americana“ einem rein europäischen Verständnis von Romantik entgegengestellt wird.

Fray Servando Teresa de Mier wird damit in einer ganz besonderen Weise zu unserem Gewährsmann für die „amerikanische Ausdrucksweise“ an einer Scharnierstelle zwischen dem 18. und dem 19. Jahrhundert. In eben dieser Funktion ist er für unsere Sichtweise einer „Aufklärung zwischen zwei Welten“ von großem Interesse - und nicht nur als ein später Teilnehmer an der Polemik zwischen Europa und Amerika um die Neue Welt. Denn er steht in seinen Anfängen noch im Barockzeitalter, wird zu einem Teil jener neuspanischen Aufklärung, deren Bedeutung erst so spät in Europa erkannt zu werden beginnt, und entwickelt ausgehend von den Errungenschaften der Aufklärung ein deutlich romantisch akzentuiertes Bild von Unabhängigkeit und Freiheit, das sich mit seiner pikaresken Gestalt auf faszinierende Weise verbindet. Fray Servando vermochte es, seine persönliche Rebellion mit jenen kollektiven Freiheitsbewegungen zu verbinden, welche das Zeitalter um die Wende zum 19. Jahrhundert prägten.

Doch dieser nur kurz umrissene und skizzierte Weg war alles andere als eine Vergnügungsreise oder ein Spaziergang durch die Geschichte. Der Leidensweg von Fray Servando Teresa de Mier beginnt mit jener denkwürdigen Predigt am 12. Dezember 1794 zu Ehren der Jungfrau von Guadalupe in Mexiko-Stadt. Diese Predigt wird zum Ausgangspunkt einer jahrzehntelangen Verfolgung des Dominikaners, die mehr als die Hälfte seines über sechzig Jahre langen Lebens andauern wird. Aber wie konnte eine kurze Predigt eine solche Wirkung zeitigen? Und welche Bedeutung kommt ihr im Kontext der historischen, philosophischen und mentalitätsgeschichtlichen Entwicklungen jener Zeit zu?

Zunächst einmal war es nicht irgendeine Predigt in irgendeiner Kirche Neuspaniens, sondern eine Ansprache in der Kathedrale von Mexiko-Stadt und vor dem versammelten hohen Klerus des Vizekönigreichs. Fray Servando griff in seiner Predigt auf eine Tradition zurück, die sich bereits in den ersten Jahren nach der Conquista herausgebildet hatte. Auf eine Vielzahl von Analogien zwischen indigenen und christlichen Riten gestützt war die Ansicht entstanden, dass der Neue Kontinent bereits vor Ankunft der Spanier christianisiert worden beziehungsweise mit der christlichen Lehre in Verbindung gekommen sei. ${ }^{9}$ Dies war kein harmloser Gedanke oder eine bloße Einzelmeinung: Eine solche Anschauung barg in den Augen des herrschenden kolonialspanischen Systems Sprengstoff pur.

Fray Servando muss dies sehr wohl klar gewesen sein. Dennoch griff er im Angesicht des spanischen wie des neuspanischen Klerus auf dieses Erklärungs-

9 Vgl. hierzu auch Todorov, Tzvetan: Die Eroberung Amerikas. Das Problem des Anderen. Aus dem Französischen von Wilfried Böhringer. Frankfurt am Main: Suhrkamp 1985, S. 246-250. 
muster zurück, ein Ideologem, das ihn ohne jeden Zweifel als Neuspanier auswies. Der junge Dominikaner verteidigte den Glauben und die Überzeugung, die Erscheinung der Jungfrau von Guadalupe - die längst schon zur Patronin Mexikos und, wenn man so will, zu einer nationalen Symbolfigur geworden war - ginge auf die vorspanische Zeit zurück. Auch das von ihr hinterlassene Bildnis stamme nicht aus der Epoche nach der spanischen Eroberung, sondern entspringe einer ersten christlichen Missionierung Amerikas durch den Heiligen Thomas, den man später unter dem Namen des Quetzalcóatl weiterverehrt hätte. Damit bezog Fray Servando ein wichtiges Element der „Religiosidad popular“ und den - aus offizieller kirchlicher Sicht - ,Aberglauben‘ der indigenen Bevölkerung ein:

\begin{abstract}
Aus diesem Grunde schlug ich zwei wahrscheinliche Propositionen oder Setzungen vor, auf die sich in der Substanz die ganze Predigt reduzierte. Das Übrige waren lediglich Episoden von geringer Wichtigkeit, um einige Löcher zu stopfen, welche die Kritik in der Tradition freigelegt hat. die erste war, dass das Evangelium in Amerika bereits Jahrhunderte vor der Eroberung durch den Heiligen Thomas gepredigt wurde, den die Indianer bereits Santo Tomé auf Siriakisch nannten. Weil Quetzal auf Grund der Kostbarkeit der Federn des Quetzalli auf den aztekischen Bildern dem Heiligenschein unserer Heiligen entsprach, so wie Ranken und Strahlen um ein Gesicht ein distinktives Merkmal der Gottheit bilden, wobei dies folglich so viel meinte wie Heiliger. Und coatl, korrumpiert coate, bedeutet dasselbe wie Tomé, das heißt Zwilling, durch die Wurzel taam, denn auf Hebräisch sagt man Thama oder Taama, und mit griechischen Anklängen Thomas, den die Griechen aus demselben Grunde in ihrer Sprache auch Dydimo nannten. ${ }^{10}$
\end{abstract}

Die gelehrten Ausführungen von Fray Servando, der das Griechische und Hebräische, aber auch die indigenen sprachen in dieser Passage anführt, können nicht darüber hinwegtäuschen: Der neuspanische Dominikanermönch eignete sich damit eine volksreligiöse Tradition an, die zweifellos einen gewissen Verbreitungsgrad im damaligen Neuspanien gehabt haben dürfte. Aber er tat dies nun vom Standpunkt der offiziellen Katholischen Kirche aus, die zu den wichtigsten Stützpfeilern der spanischen Kolonialherrschaft in den Amerikas zählte. Das war bei aller vorgeschobenen Gelehrsamkeit fürwahr unerhört für die versammelte klerikale Gemeinschaft. War sich der junge Prediger Fray Servando Teresa de Mier dieser Tatsache bewusst? Oder tat der damals achtundzwanzigjährige Geistliche ganz bewusst diesen Schritt in eine offene Rebellion gegen die herrschende katholische Lehrmeinung oder Doxa?

Diese Frage ist bis heute nicht abschließend geklärt und wird sich wohl auch nie eindeutig klären lassen. Denn diese synkretistische Verbindung zweier

10 Mier, Fray Servando Teresa de: Memorias, Bd. 1, S. 20. 
volksreligiöser Traditionen zu einer letztlich protonationalen Symbolik ${ }^{11}$ - vergessen Sie nicht, dass die Virgen de Guadalupe noch im heutigen Mexiko die Verkörperung der Nation ist und eine ungeheure Ausstrahlungskraft besitzt! bezog ihre politische Explosivität daraus, dass die Verlegung der göttlichen Erscheinung in die vorkolumbische Zeit einer heilsgeschichtlichen Legitimation der spanischen Conquista logischerweise den Boden entzog. Die spanischen Eroberer begründeten ihre Unterwerfung der indigenen Bevölkerungen ja gerade damit, sie von barbarischen Religionen erlöst und ihnen den christlichen Glauben gebracht zu haben. Diesen Stützpfeiler der herrschenden spanischen Macht zu attackieren, war zumindest subversiv, vielleicht sogar revolutionär. Denn damit war das zentrale Ideologem des spanischen Kolonialismus berührt und eine göttliche Rechtfertigung jeglicher spanischen Herrschaft auf dem amerikanischen Kontinent in Frage gestellt. Fray Servando Teresa de Mier musste dies in seiner Logik sehr wohl klar gewesen sein, weniger aber vielleicht die Härte der Konsequenzen, die sich daraus für ihn und seine Laufbahn beziehungsweise sein weiteres Leben ergaben.

Denn der bei der Predigt anwesende höhere, aus Spanien stammende Klerus erkannte diese Gefahr und reagierte umgehend: Erzbischof Núñez de Haro ließ gegen diese, dem kreolischen Selbstverständnis entsprungene Vorstellung und ihren Vertreter predigen und entzog Fray Servando bereits am folgenden Tage die „missio canonica“. Die Kirche reagierte schnell, denn es waren für die spanische Kolonialmacht gefährliche Zeiten: Es brodelte in den kreolischen Eliten im gesamten Kolonialreich. So griff der spanische Dienstvorgesetzte von Fray Servando hart durch und wollte ein Exempel statuieren, um andere kreolische Kleriker mit ähnlichen Vorstellungen abzuschrecken.

Diese Verhaltensweise war durchaus rational. Wenn man sich die besondere Rolle, die der mexikanische Klerus wenige Jahre später bei der Unabhängigkeitsrevolution in Neuspanien spielte, vor Augen hält, so erscheint die Reaktion des Kirchenoberen aus dessen Perspektive als sehr wohl verständlich. Gewiss handelte es sich nur um eine mündliche Predigt - doch sie konnte ungesühnt wie ein Fanal wirken. Eine erzwungene Widerrufung seiner Position, die der junge Dominikaner mit dem Hinweis auf die Ungemütlichkeit des Gefängnisses begründete, änderte

11 Vgl. Reyes, Alfonso: Prólogo a Fray Servando. In (ders.): Obras completas. México: Fondo de Cultura Económica 1956, S. 552. Dort auch weiterführende Literatur zur Jungfrau von Guadalupe; zur politischen Dimension des Marienkultes vgl. Aguila, Yves: Sur les prémices d'un sentiment national en Nouvelle Espagne (1805-1810). In: Pérez, Joseph et al. (Hg.): Esprit créole et conscience nationale. Essais sur la formation des consciences nationales en Amérique Latine. Paris: Editions du Centre National de la Recherche Scientifique 1980, S. 69-96. 
nichts mehr an der Entscheidung: Fray Servando Teresa de Mier wurde $1795 \mathrm{zu}$ zehnjähriger Verbannung nach Spanien in ein Kloster bei Santander verurteilt.

In seinen Memorias beschäftigte sich Fray Servando durchaus gleich zu Anfang mit seiner eigenen Predigt, spielte deren Bedeutung aber eher herunter, um die ihm widerfahrene Ungerechtigkeit in umso grellerem Licht erscheinen zu lassen. Doch fügte er auch andere Überlegungen mit an, welche geeignet waren, die beherrschende Rolle Spaniens seit der sogenannten Entdeckung und Eroberung herabmindern zu können. In diesem Zusammenhang lesen wir in seinen Memoiren:

Darüber hinaus war es auch noch leicht, nach Amerika zu gelangen, indem man die kleine Meerenge durchquerte, die es von Asien trennt, oder indem man von Insel zu Insel hüpft, insofern es zwischen beider Küsten eine Kordillere gibt, und dies auf den Schiffen von China, das in den ersten Jahrhunderten des Christentums in Verbindung mit beiden Amerikas stand. Dies steht laut Monseigneur Wache fest, der in Peking selbst die geographischen Karten der Chinesen studierte und in seiner Abhandlung über eine unbekannte Insel, welche er vor dem Institut National de France präsentierte und die unter den dortigen Mémoires im Druck erschien; er berichtet von den Namen, welche die Chinesen beiden Amerikas gaben, und beschreibt die Route, auf der sie kamen, und er berichtet sogar, dass im Jahre 450 des Herrn Jesus Christus Geistliche in unser Amerika kamen, wo sie die Religion von Joë verbreiteten, welche der christlichen sehr ähnlich ist und daher von ihm leicht mit jener verwechselt werden konnte. $^{12}$

Diese Passage ist im Kontext unserer Vorlesung überaus spannend. Denn zusätzlich zu den ,beiden Welten' erscheint hier eine ,dritte Welt', die viel früher als die Spanier und Europa nach Amerika gekommen ist: Asien - und dabei an erster Stelle China. Fray Servando Teresa de Mier bezieht sich in seinen Memorias auf eine am renommierten „Institut“ in Paris präsentierte Abhandlung über eine frühe ,Entdeckung Amerikas durch chinesische Seefahrer; eine Tatsache, die von der heutigen Historiographie längst bestätigt wurde und die dem Dominikaner dazu dient, die sogenannte ,Entdeckung‘ Amerikas durch Christoph Kolumbus und die Spanier in ihrer Bedeutung ebenso herunterzuspielen wie die Christianisierung der amerikanischen Völker, die lange Jahrhunderte vor den Spaniern bereits durch die Chinesen mit ihrer Religion erfolgt sei.

Auf den ersten Blick könnte es sich hierbei um eine Anekdote, um eine kleine Episode oder um eine mehr oder minder disparate Einzelmeinung handeln. Doch Fray Servandos These entspricht der bei den neuspanischen Kreolen verbreiteten Überzeugung, sich nicht nur in der Mitte der amerikanischen Hemisphäre, sondern auch im Zentrum der Welt zwischen Europa und Asien zu befinden und von daher ausgezeichnete Möglichkeiten in Handel, Wirtschaft und Politik zu besitzen, wäre die lästige koloniale Abhängigkeit von Spanien erst einmal überwunden. In

12 Mier, Fray Servando Teresa de: Memorias, Bd. 1, S. 31. 
einer langen historischen Tradition verstand sich Mexiko als das Zentrum aller vier Weltteile, die unseren Planeten noch über weite Strecken des 18. Jahrhunderts bildeten. Wie sehr sich der neuspanische Dominikaner längst mit diesem Amerika identifizierte, macht auch die Verwendung des Begriffs „Nuestra América“ deutlich: ein Begriff, der für die Identifizierung der Kreolen nicht mit der spanischen Herrschaft, sondern mit dem eigenen Amerika zeugt und im 19. Jahrhundert - ich habe darauf in meiner Vorlesung über die Romantik zwischen zwei Welten hingewiesen ${ }^{13}$ - eine enorme Bedeutung erhalten sollte. Fray Servando drückte in dieser Passage folglich das aus, was eine kreolische Elite in Neuspanien wie in den Amerikas insgesamt empfand und dachte.

Kommen wir an dieser Stelle wieder zurück zur weiteren Entwicklung des Lebens unseres Dominikanermönchs! Mit der Verurteilung und der Verbannung beginnt jener zentrale Abschnitt in seinem Leben, der ihn nach Europa, genauer: nach Spanien, Frankreich, Italien, Portugal und England führen sollte. Fray Servando steht genau im Fadenkreuz jener transatlantischen Beziehungen, welche sich bereits im Vorfeld der Unabhängigkeitsbestrebungen grundsätzlich verändert hatten und die die spanische Kolonialherrschaft über Neuspanien in der Tat ins Wanken bringen sollten. Spanien war im Zuge des erwähnten geokulturellen Dominantenwechsels schon lange nicht mehr das geistige Mutterland der in Amerika geborenen Kreolen.

Diese sogenannte ,Reise' des Dominikaners, die nichts anderes als eine nie enden wollende Kette von Verfolgungen, Gefängnisaufenthalten und erstaunlicherweise immer wieder gelingenden Ausbruchsversuchen war, steht unter einem ganz anderen Zeichen als Alexander von Humboldts Reise in die Neue Welt, die fast zeitgleich stattfand und mit der Fray Servandos Bewegungen durch Europa in stärkstem Kontrast stehen. ${ }^{14}$ Der Unterschied wird bereits im Titel deutlich: Denn war die Reise in die Äquinoktial-Gegenden von Humboldt und Bonpland ab 1799 eigenständig unternommen worden, so lautet das Kernstück der sogenannten $M e$ moiren des Dominikaners Relación de lo que sucedió en Europa al Doctor Don Servando Teresa de Mier después que fué trasladado allá por resultas de lo actuado contra él en México, desde julio de 1795 hasta octubre de 1805.

Der fundamentale Blickwechsel gegenüber der Humboldt'schen Reise durch die amerikanischen Tropen ist bei Fray Servandos Inhaftierungs- und Fluchtbewegungen quer durch Europa offenkundig. Die zehnjährige Flucht bewegt sich nicht

13 Vgl. Ette, Ottmar: Romantik zwischen zwei Welten, S. $342 \mathrm{ff}$.

14 Vgl. hierzu erstmals Ette, Ottmar: Der Blick auf das Andere. Eine kontrastive Lektüre der Reisen Alexander von Humboldts und Fray Servando Teresa de Miers. In: Schlieben-Lange, Brigitte et al. (Hg.): Europäische Sprachwissenschaft um 1800. Bd. 2: Methodologische und historiographische Beiträge zum Umkreis der ,idéologie“. Münster: Nodus Publikationen 1991, S. 137-171. 
entlang eines vorberechneten Planes, sondern angetrieben vom ständigen Aufbegehren und der Rebellion gegen die bestehenden Herrschaftsstrukturen und so vieles in Europa, das mit der kolonialen Unterdrückung von Nuestra América in Verbindung steht. Die passiven Verbformen drücken deutlicher als alles andere die Unfreiwilligkeit des ganzen Geschehens aus, von dem Fray Servando berichtet. Denn 1795 beginnt für den Kreolen eine Odyssee, die ihn erst nach langen Jahren wieder in die Heimat, in sein Ithaka, zurückführen sollte. Es handelte sich bei weitem nicht um eine Forschungsreise, sondern zunächst um eine Überstellung in ein spanisches Gefängnis zur Umerziehung eines aufmüpfigen Klerikers, den man im Mutterland wieder zur Räson bringen wollte. Doch die Unterdrückung, die sich hautnah am Körper des Kreolen vollzieht, steht für die Unterdrückung seiner amerikanischen Heimat, für die der kreolische Kleriker immer mit neuem Elan eintritt.

Ist der erste Teil der Relación noch ganz autobiographischen Darstellungsformen verpflichtet und versucht er, den Leser zum Zeugen der Unschuld des Autors zu machen - so wie Rousseau in den Confessions einst mit dem Buch in der Hand der Gerechtigkeit teilhaftig werden wollte -, so tendiert der Text in seinem weiteren Verlauf immer stärker zu deskriptiven Formen, zu einem wenn auch manchmal phantasievoll ausgeschmückten (da den phantastischen Reisebeschreibungen nachempfundenen) Reisebericht, ja zum Versuch einer Darstellung der bereisten europäischen Länder, die auf irgend eine Weise stets mit der Kolonialherrschaft Spaniens über Neuspanien verbunden sind. Vor diesem Hintergrund vollzieht sich der radikale Blickwechsel, den die Memorias des Fray Servando in Europa nun für ein vorwiegend amerikanisches Lesepublikum vollziehen.

Fray Servando beschrieb in seinen Memoiren freilich weder Natur noch Landschaft; es standen vielmehr politische und administrative Vorgänge und Gegebenheiten sowie Sitten und Bräuche im Vordergrund aller Beschreibungen. Die Geographie Spaniens, die Fray Servando höchst schmerzhaft, „a golpes y palos“15 auf seinen erzwungenen Reisen erlernte, interessiert ihn freilich kaum. So hält er auch die Sierra de Guadarrama, verantwortlich für die den Kreolen so schreckende Kälte von Madrid, für einen Ausläufer der Pyrenäen. ${ }^{16}$ Doch verzeihen wir ihm das, da erst mit den barometrischen Höhenmessungen von Humboldt im Jahre 1799 erstmals klar wird, in welcher Höhenlage sich Zentralspanien mit seinen Mesetas befindet. Das Mutterland des spanischen Imperiums war geographisch weitaus weniger bekannt und vermessen als etwa das benachbarte Frankreich. Verwunderlich ist diese Fehleinschätzung angesichts der mangelnden geographischen Kenntnis Spaniens um die Jahrhundertwende nicht, hatte die spanische Kolonialmacht doch zwar die Kolonien und die

15 Mier, Fray Servando Teresa de: Memorias, Bd. 2, S. 244: „mit Schlägen und Knüppeln.“ 16 Ebda., Bd. 2, S. 188. 
Schifffahrtswege dorthin auf immer präziser werdenden Karten genau vermessen, darüber aber die Untersuchung des eigenen Landes stark vernachlässigt. Gegenüber den beherrschenden Mächten der zweiten Phase beschleunigter Globalisierung, mithin gegenüber England und Frankreich, war Spanien im aufklärungszeitalter in die zweite Reihe verbannt.

Dieses Spanien erscheint aus der Perspektive des amerikanischen Kreolen als durch und durch korrupt. So schildert Fray Servando, wie ihm die Augen über die korrupte Kolonialverwaltung in Spanien erst spät aufgegangen seien, weswegen er es für umso wichtiger halte, diejenigen seiner Landsleute mit Hilfe seiner Schriften zu öffnen. Denn das aus amerikanischer Perspektive so glänzende Spanien erscheint, in seiner Macht aus der Nähe betrachtet, eher als heruntergekommen und provinziell:

Damals war es, als ich die Augen mit Blick auf die Praxis unserer Regierung öffnete und zugleich auf die Hilfsmittel, welche den Amerikanern auf beiden Wegen, dem geheimen und dem über den Consejo de Indias, zur Verfügung stehen, um ihre Einnahmen und Dringlichkeiten zu sichern, und so wird es gut sein, dass ich meinen Landsleuten die Augen öffne, damit sie absolut niemals darauf vertrauen, Gerechtigkeit zu erlangen, da dieses nur dann gilt, wenn große Gunst oder viel Geld herrscht, damit sie versuchen, hier ihre Klagen soweit sie es können durchzusetzen, selbst bei schlechter Zusammenstellung. Denn dort ist die Macht absoluter, und der Hof und die Tribunale sind käuflicher, und größer die Zahl der Bedürftigen, der Übelwollenden und der Intriganten, so dass die Hilfsmittel schwieriger um nicht zu sagen unmöglich sind für einen Armen, also in einem Wort: Dort geht es nicht um das Gewissen, sondern um Geld und Politik, denn beim Spiel der Intelligenz und Verhalten der Höfe geht es just um das Gegenteil der Moral. ${ }^{17}$

Diese Passage ist für die Sichtweise der „Madre Patria“ durch den Dominikaner charakteristisch. Die hier von Fray Servando angesprochenen „paisanos“ sind die Bewohner jenes Gebietes, das der Mexikaner immer wieder als „Nuestra América““18 bezeichnet. Der Ausdruck, der sich in den spanischen Kolonien der Neuen Welt bis ins 17. Jahrhundert schriftlich zurückverfolgen lässt, zeugt - wie bereits betont von der beginnenden Identifikation der Kreolen mit ihrem Kontinent und ihrem Geburtsort. ${ }^{19}$ Am Ende des 18. Jahrhunderts, also am Vorabend der Unabhängigkeitsrevolution der spanischen Kolonien, war „Nuestra América“ zu einem wichtigen Bestandteil des Vokabulars der (in der Neuen Welt geborenen) Kreolen geworden. Fray Servando war zweifellos auch auf Ebene der von ihm gewählten Begrifflichkeit Teil jener revolutionären Trägerschicht, für die er in seinen Schriften die Stimme erhob.

17 Ebda., Bd. 1, S. 243.

18 Vgl. etwa auch ebda., Bd. 2, S. $173 \mathrm{ff}$.

19 Vgl. Almarza, Sara: La frase „Nuestra América“: historia y significación. In: Caravelle 43 (1984), S. 5-22. 
Er unternimmt in der obigen Passage den Versuch, seine Landsleute vor einer absichtsvoll fehlenden Gerechtigkeit im spanischen Mutterland zu warnen, indem er die Korruption und Käuflichkeit in den kolonialen Strukturen der iberischen Kolonialmacht demaskiert. Jegliches Vertrauen in eine wie auch immer geartete Gerechtigkeit am spanischen Hofe zu Madrid sei bei seinen „paisanos“ daher nachweislich fehl am Platze. Fray Servando wusste sich in derlei Einschätzungen aber nicht nur mit vielen seiner Landsleute vereint, sondern auch mit jenen Vertretern einer spanischen Aufklärung, die sich für grundlegende Reformen in Spanien stark machten und die spanische Herrschaftsstruktur einer scharfen aufklärerischen Kritik unterwarfen, welche die Brüchigkeit der spanischen Monarchie noch vor den Niederlagen gegen Napoléons Armeen aufzeigte.

Fray Servandos Spanienbild ist von Sittenverfall und moralischer Degenerierung, von abscheulicher sexueller Freizügigkeit insbesondere bei den Spanierinnen und von einem ruhelosen Ausrauben der Kolonien bestimmt, welche sich endlich zur Wehr setzen müssten. Spanien wird in Wirklichkeit nicht von seinem König, auch nicht von seinen Ministern, sondern von den Beamten am Hofe regiert, den „,covachuelos“. ${ }^{20}$ Gegen diese aber richtet sich der ganze Hass des Kreolen. Denn von ihnen ist keinerlei Gerechtigkeit zu erwarten, herrschen in ihren Kreisen doch Verleumdung, Täuschung und Korruption ohne Ende vor. Der ganze Hof ist in den Augen des neuspanischen Denkers nichts anderes als ein einziges Bordell. ${ }^{21}$ Wer als Amerikaner angesichts dieser Zustände noch an Gerechtigkeit oder eine moralische Legitimation des Mutterlandes glaubt, müsse dringend eines Besseren belehrt werden. ${ }^{22}$

Die politische, moralische und religiöse Dekadenz Spaniens, des Feindes der menschlichen Vernunft, wird in allen Schriften des Dominikaners immer wieder herausgestrichen. Fray Servando Teresa de Mier erweist sich in all diesen Argumentationen nicht nur als Anhänger der neuspanischen Aufklärung, sondern als ein authentischer Vertreter dieser „filósofos“, welchem freilich noch immer die Hoffnung eignet, bei Gleichgesinnten in Spanien Unterstützung zu finden. Dabei verwendet der von der neuspanischen Kirche verstoßene Kleriker argumentative Schemata, wie sie für die Aufklärung charakteristisch sind. In seiner Apología etwa bedient sich Fray Servando eines Grundschemas der Selbstverteidigung, das sich bereits in den Kapitelüberschriften dieses Werkes abzeichnet, welche kurz ange-

20 Mier, Fray Servando Teresa de: Memorias, Bd. I, S. 234, 241 u. $244 \mathrm{ff}$.

21 Ebda., Bd. 2, S. 166.

22 Ebda., Bd. 1, S. 243. 
führt seien: „Die Leidenschaften verschwören sich, um gegen die Unschuld vorzugehen“; „Die Leidenschaften verleumden die Unschuld“; „Die Leidenschaften beleidigen die Unschuld“; „Die Leidenschaften kriminalisieren die Unschuld““ ${ }^{23}$ Es gefiel dem auf all seinen Wegen in Europa Verfolgten stets, sich im Gewand einer verfolgten Unschuld, einer „vertu persécutée“, ganz so darzustellen, wie dies in der französischen Aufklärungsliteratur der Fall war. Erinnert sei hier nochmals an die klugen Einschätzungen des Kubaners José Lezama Lima, der in La expresión americana treffend formulierte: „Fray Servando war der erste Entflohene, ausgestattet mit der notwendigen Kraft, um zu einem Ende zu gelangen, welches alles klärt, von der barocken Herrlichkeit an, vom Herren, der den wollüstigen Dialog mit der Landschaft durchquert. Er war der Verfolgte, welcher aus seiner Verfolgung eine Art der Integration macht.“24

Das Grundschema verfolgter Tugend ist uns aus der französischen Aufklärung wohlvertraut, bedienten sich doch die „philosophes“ von Voltaire oder JeanJacques Rousseau bis hinunter zum unwichtigsten Provinzphilosophen des legitimierenden Bildes der „vertu persécutée“, um ihren selbstlosen Einsatz für ihre Ideen dem Publikum glaubhaft zu machen..$^{25}$ Gerade die Argumentationen des Genfer Philosophen bringen an dieser Stelle eine Emotionalisierung des Diskurses zum Tragen, der just in der Romantik auf starke Zuneigung stoßen sollte. Ungezählte Male in seinen Memoiren beschwor Fray Servando seine geradezu kindliche Einfalt und Unschuld ${ }^{26}$ seine „,santa sencillez“ ${ }^{27}$ seinen „candor natural“, ${ }^{28}$ „el candor que se notó casi siempre en todos los grandes ingenios“29 und bemühte gar das Rousseau entliehene Bild der Ameisen, die er auf seinen Wegen sorgfältig umgehe, um sie nicht zu verletzen. ${ }^{30}$ Dieser Aspekt der Stilisierung der eigenen Persönlichkeit ist als Waffe im Kampf gegen alle Formen der Unterdrückung wich-

23 „Las pasiones se conjuran para procesar a la inocencia“; „Las pasiones [...] calumnian a la inocencia“; „Las pasiones infaman la inocencia“; „Las pasiones acriminan la inocencia“.

24 Lezama Lima, José: La expresión americana, S. 97: „Fray Servando fue el primer escapado, con la necesaria fuerza para llegar al final que todo lo aclara, del señorío barroco, del señor que transcurre el voluptuoso diálogo con el paisaje. Fue el perseguido, que hace de la persecución un modo de integrarse.“

25 Vgl. hierzu etwa Gumbrecht, Hans Ulrich / Reichardt, Rolf: Philosophe, Philosophie. In: Handbuch politisch-soziale Grundbegriffe in Frankreich: 1680-1820. Herausgegeben von Rolf Reichardt und E. Schmitt. Fasc. 3. München: Oldenbourg 1985, S. 47.

26 Mier, Fray Servando Teresa de: Memorias, Bd. 2, S. 227.

27 Ebda., Bd. 2, S. 232.

28 Ebda., Bd. 2, S. 241.

29 Ebda., Bd. 2, S. 239.

30 Ebda., Bd. 2, S. 10. 
tig, verweist uns aber auch darauf, dass wir es bei dem neuspanischen Dominikaner mit einem Philosophen im Sinne moderner Subjektivität zu tun haben.

Seine Argumentationsstrategie enthielt freilich noch ein zusätzliches Element. Fray Servando ergänzte die von den Aufklärern benutzte Rechtfertigungsstrategie nämlich durch die Komponente seiner Amerikanität. Er vertrat gegenüber den Leidenschaften der moralischen Dekadenz in Spanien das Recht der ,virtud americana perseguida“, der verfolgten amerikanischen Tugend. Allein auf Grund seiner bewussten Amerikanität werde er verfolgt und zum bevorzugten Gegenstand aller Benachteiligungen: „Wenn sich ein böswilliges Spanierlein mit mir hätte aussprechen wollen, hätte ich ihm meine kurzen Zeilen gezeigt, ihn über alles unterrichtet und seiner Provinz die Ausgaben für meine Spesen erspart. Aber was gibt man einem Spanierlein aus der Provinz, aus der er stammt? Das Geschäft besteht ja gerade darin, den Kreolen zu verfolgen [...].،31

Die Grenze nach Frankreich, der Heimstätte der Aufklärung, passierte Fray Servando Teresa de Mier auf eben jene Weise, in der einst Jean-Jacques Rousseau dasselbe Frankreich verlassen hatte, um sich der Verfolgung durch seine Flucht in die Schweiz zu entziehen: Er ließ sich den genauen Verlauf der Grenzlinie zeigen, überschritt sie und küsste dann euphorisch den Boden des freien Landes. ${ }^{32}$ JeanJacques Rousseau ist in den Schriften des Mexikaners weitaus präsenter, als dies auf den ersten Blick erscheinen möchte - und als es Fray Servando vielleicht selbst auch wahrhaben wollte. Rousseaus philosophische wie mentalitätsgeschichtliche Bedeutung weit über die Epoche der Aufklärung und weit über die Grenzen Europas hinaus wird auch an dieser Tatsache sehr deutlich.

Rousseaus Einfluss lässt sich zweifellos auch bei einem der wichtigsten Vertreter der spanischen Aufklärung konstatieren, mit dem wir in dieser Vorlesung wieder nach Europa zurückkehren. Freilich in ein Europa, das im Siècle des Lumières so sehr an den Rand Europas und der europäischen République des Lettres gerückt war, dass bisweilen in der Forschung gar an der Existenz einer Aufklärung in Spanien gezweifelt werden konnte. Doch derlei Fehleinschätzungen sind längst, auch im Nachbarland Frankreich, vom Tisch und wir verstehen heute die transatlantischen Verbindungen zwischen der spanischen und der neuspanischen Aufklärung sowie den Aufklärern aus unterschiedlichen Areas der kolonialspanischen Territorien in Amerika weitaus besser.

31 Mier, Fray Servando Teresa de: Memorias, Bd. 2, S. 232: „A no ser un gachupín malignante se hubiera explicado conmigo, le hubiera mostrado mis breves líneas, instruídole de todo, y ahorrado a su Provincia el gasto de mi manutención. Pero ¿qué se le da a un gachupín de la Provincia de que es ahijastro? El negocio es perseguir al criollo [...].“

32 Ebda., Bd. 2, S. 17. 
Als vielleicht repräsentativstes Beispiel für einen in Spanien wirkenden Aufklärer möchte ich Ihnen gerne José Cadalso vorstellen, der überdies für uns den Vorteil besitzt, ein Werk geschrieben zu haben, das sich in unmittelbarer Verbindung - man könnte fast sagen in einem kritischen Dialog - mit den Lettres persanes von Montesquieu lesen lässt, mit denen wir uns ja zu Beginn unseres Weges durch die Aufklärung zwischen zwei Welten auseinandergesetzt haben.

José Cadalso y Vázquez de Andrade wurde am 8. Oktober 1741 im andalusischen Cádiz geboren und verstarb bei einem tragischen Geschehen am 26. Februar 1782 bei der Belagerung von Gibraltar. Er entstammte einer reichen Kaufmannsfamilie, die sich väterlicherseits vom Señorío de Vizcaya ableitete, so dass man ihm dem Adel zurechnen darf. Mit Rousseau verbindet ihn bereits das Schicksal, dass - wie er selbst schrieb - seine Mutter bei seiner Geburt zu einem Zeitpunkt verstarb, als der Vater geschäftlich in den amerikanischen Kolonien beschäftigt war. So kam es, dass der Sohn ohne Mutter aufwuchs und seinen Vater erst mit dreizehn Jahren kennenlernte: Sein Onkel, der Jesuit Mateo Vázquez, kümmerte sich liebevoll um den verwaisten Jungen und dessen Erziehung. Dieser Onkel war ein „hombre de letras“, der es bis zum Rektor des Colegio de Jesuitas in Cádiz brachte und dem Jungen die bestmögliche Ausbildung zukommen lassen wollte.

Er schickte den hochbegabten Jungen zur weiteren Ausbildung nach Paris ans Lycée Louis-le Grand, eine französische Eliteeinrichtung, die ebenfalls von Jesuiten geleitet wurde. In seinen Apuntaciones autobiográficas erzählt Cadalso, wie er im Alter von neun Jahren an dieses Lycée kam, als der Père Latour der Einrichtung vorstand, der auch Protecteur Voltaires bei dessen Aufnahme in die Académie war. So genoss der junge Cadalso eine mit den brillantesten französischen Aufklärern vergleichbare Ausbildung. Als der Vater wieder nach Europa zurückkehrte, folgte ihm sein Sohn nach London, später nach Italien, Deutschland, Holland und schließlich wieder nach Spanien, wo der junge Mann zu Madrid in das Seminario de Nobles eintrat. José Cadalso galt seinen Mitschülern als europäisierender Kosmopolit, der über einen wesentlich breiteren Erfahrungshorizont als sie selbst oder ihre Lehrer verfügte und feinste Manieren besaß. Spanien freilich war dem jungen Mann nach eigener Aussage vollständig fremd geworden.

José Cadalso aber fügte sich jedoch, den Befürchtungen seines Vaters zum Trotz, in Spanien wieder bestens ein und lebte als junger modebewusster Adeliger in einer Umgebung, in der er schon durch seine Fremdsprachen, aber auch durch seine literarische Bildung herausstach. Auch durch spätere Reisen war es der junge José Cadalso gewöhnt, zwischen verschiedenen kulturellen und sprachlichen Welten zu leben. Da sein Vater die militärische Berufung und den kriegerischen Enthusiasmus seines Sohnes fürchtete, schickte er ihn erneut ins Ausland, so dass er im Alter von achtzehn bis zwanzig Jahren erneut in Paris und in London lebte, wo er seine literarische Bildung erweitern konnte. Doch nach der Nachricht vom Tode sei- 


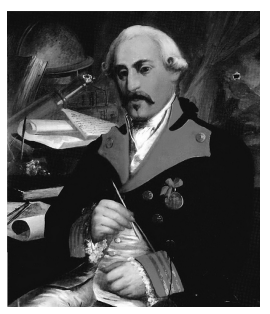

Abb. 40: Pablo de Castas Romero: Postumes Portrait von José Cadalso (1741-1782).

nes 1761 in Dänemark verstorbenen Vaters kehrte er nach Spanien zurück, wo er freiwillig in das Kavallerieregiment eintrat, das in den Feldzug gegen Portugal 1762 eingriff. Cadalsos Leben stand künftig im Zeichen der in Spanien vielberufenen „Armas y Letras“, der Kriegs- und der Dichtkunst.

Gemessen an seinen hohen Ansprüchen, ging es mit der militärischen Karriere freilich nur langsam voran. Cadalso sucht nach neuen Verbindungen auch bei Hofe. 1766 lernt er in Alcalá Gaspar Melchor de Jovellanos kennen, eine für seine aufklärerische Ausrichtung entscheidende Bekanntschaft. Jovellanos erinnert sich, dass Cadalsos „Ingenio“ schon damals gerühmt wurde, und er selbst habe sich der Poesie nach diesem Vorbild zugewandt. Im selben Jahr noch wird der Capitán und Dichter zum Ritter des Santiago-Ordens geschlagen und kommt in Kontakt mit dem Conde de Aranda, dem nach dem Fall von Esquilache neuen starken Mann unter dem Aufklärer-König Carlos III. Aranda wurde 1767 die Aufgabe der Ausweisung der Jesuiten aus Spanien und den spanischen Kolonien übertragen, eine für die Aufklärungsepoche im spanischsprachigen Bereich wichtige Entscheidung von epochaler Bedeutung auf beiden Seiten des Atlantik. Wir hatten in unserer Vorlesung etwa Francisco Javier Clavijero als einen jener Jesuiten kennengelernt, der sein Werk über die alte Geschichte Mexikos aus diesem Grunde im italienischen Exil verfassen musste. Cadalso verdankte seine blendende Ausbildung eben diesen Jesuiten, doch empfand er wenig Mitleid mit den Angehörigen der Compañía de Jesús, über die er manch spöttische Bemerkung verlor.

Auf Grund einer satirischen Darstellung der amourösen Sitten am Hofe, die man mit seinem Namen in Verbindung brachte, wurde Cadalso für einige Zeit nach Zaragoza verbannt. Dort war auch von Teilnahmen an den für Spanien charakteristischen „Tertulias“33 die Rede, die der auch im Salon der Duquesa de Benavente Erfahrene geflissentlich porträtierte. All diese Erfahrungen sollten in Cadalsos Car-

$33 \mathrm{Vgl}$. zu dieser Institution, auf die ich bereits zu Beginn unserer Vorlesung eingegangen bin, die schöne Arbeit von Gelz, Andreas: Tertulia. Literatur und Soziabilität im Spanien des 18. und 19. Jahrhunderts. Frankfurt am Main: Vervuert 2006. 
tas Marrruecas eingehen, mit denen wir uns sogleich beschäftigen werden. In seinem Exil befasste sich Cadalso intensiver mit der Dichtkunst. Auch verband ihn zunehmend eine Freundschaft mit Nicolás Fernández de Moratín, möglicherweise durch Vermittlung des Conde de Aranda. Der oft elegant gekleidete junge Mann ging zunehmend in seinem eigenen Schreiben und im literarischen Leben Spaniens auf. Doch waren auch in der sechsmonatigen Verbannung in Zaragoza seine militärischen Hoffnungen nicht verschwunden.

Nach dem Ende der Verbannung und der Rückkehr nach Madrid stößt Cadalso zu Beginn der siebziger Jahre erstmals auf finanzielle Probleme. Doch diese Zeit wird überstrahlt von seiner Liebschaft mit einer der berühmtesten Schauspielerinnen der Epoche, María Ignacia Ibáñez, die als „Filis“ in seiner Lyrik präsent ist. Es ist die große Liebe seines Lebens, doch wird die Idylle durch den unerwarteten Tod der Schauspielerin an Typhus im Alter von fünfundzwanzig Jahren auf tragische Weise im April 1771 zerstört. Cadalso ist schwer getroffen. Zudem erregt diese Liaison Unwillen bei der Gesellschaft am spanischen Hofe, da er Angehöriger des Militärs und Ritter des Santiago-Ordens ist, so dass diese Liebesbeziehung mit einer einfachen Schauspielerin als unschicklich empfunden wurde. Für Cadalso aber war die junge Schauspielerin die begabteste Frau, die er je kennengelernt hatte und die nach seiner Aussage die Extravaganz besaß, sich in ihn zu verlieben, als er finanzielle Probleme hatte und gesellschaftlich in Zusammenhang mit seiner sechsmonatigen Verbannung eher marginalisiert war. Aber diese Liebe von nur wenigen Monaten prägte den Schriftsteller zutiefst. Noch seine Noches lúgubres können auf diesen autobiographischen Schicksalsschlag als Ausgangspunkt zurückgeführt werden.

José Cadalso war ein prominentes Mitglied der berühmten Tertulia de la Fonda de San Sebastián, an der auch sein Freund Nicolás Fernández de Moratín teilnahm. Der Beginn dieser hochgespannten Tertulia lag in dem Zeitraum, als der Conde de Aranda 1773 als Botschafter nach Paris geschickt wurde. Diese Tertulia erwies sich als literarisch höchst produktiv, da neben Iriarte oder Moratín auch Cadalso mit seinen Cartas Marruecas brillierte, die freilich zu Lebzeiten des Autors nicht mehr veröffentlicht wurden. Längst gehörte Cadalso zu den literarischen und politischen Zirkeln der spanischen Aufklärung.

Die Zeit im aragonesischen ,Exil' bedeutete für Cadalso den Aufbruch in seine literarisch sicherlich produktivste Periode, welche zwischen die Jahre 1771 und 1774 fällt. Es ist hier nicht der Ort, auf seine reiche lyrische Produktion, in welcher er in Spanien auch als Erneuerer auftrat, oder auf seine Theaterstücke einzugehen, die zeitgemäßen neoklassischen Vorgaben folgten. Wir wollen uns auf die Prosa konzentrieren und hierbei weniger auf seine Noches Lúgubres eingehen, die nach dem Tode ihres Autors veröffentlicht für die spanische Romantik ein wegweisender Bezugspunkt wurden, als uns vielmehr auf die Cartas Marrue- 
cas konzentrieren, für die Cadalso eine Druckerlaubnis zwar beantragte, aber niemals erhielt. Zwischen beiden Werken siedelt sich die zu Lebzeiten Cadalsos in Spanien wohl berühmteste Schrift des Autors an - Los eruditos a la violeta, mit der er aufklärerische Bildungsziele verfolgte und einer bloß oberflächlichen Bildung entschlossen entgegentrat.

José Cadalso ging enttäuscht vom spanischen Hofe und auf seine literarische Arbeit konzentriert zu seinem Regiment zurück und schloss seine Cartas Marruecas während seines kurzen Aufenthalts 1773/1774 in Salamanca ab. Während dieser kurzen Zeit wurde er zum Mittelpunkt eines Zirkels literarischer Freunde und Dichter, auf die er großen Einfluss ausübte. Von Salamanca ging Cadalso dann mit seinem Regiment nach Extremadura zu einem Zeitpunkt, als sein militärischer Enthusiasmus längst geschwächt war und bescheideneren Ansprüchen Platz machte. 1776 wurde er zum Sargento Mayor und 1777 zum Comandante de Escuadrón ernannt: Es brauchte Zeit für die erhofften Beförderungen. Um sich weiter auszeichnen zu können, bat er, an der Belagerung des noch immer von Briten besetzten Gibraltar 1779 teilnehmen zu dürfen, was gelang, so dass er als Ayudante de Campo des spanischen Generals an die Front vor Gibraltar verlegt wurde. Er soll sogar einen Plan zur Einnahme der Festung entworfen haben; einen Plan, den er an Floridablanca schickte und der eine vollständige Blockade von See wie von Land her vorsah. Doch am 26. Februar 1782 wurde er bei der Inspektion der Frontlinie von einer Granate am Kopf getroffen und verstarb - kurz nachdem er noch zum Coronel befördert worden war - im Alter von vierzig Jahren.

Cadalso war kaum dreiunddreißig Jahre alt, als er seine Cartas marruecas abschloss. Es handelt sich um jenen Text, mit dem wir uns in der Folge in der gebotenen Kürze aus der Perspektive einer Aufklärungssicht beschäftigen wollen, welche Europa im Kontext außereuropäischer Diskurse und von Diskursen über Außereuropa zu begreifen versucht. Cadalso hat diese Marokkanischen Briefe wie bereits berichtet - in Salamanca zwischen Mai 1773 und August 1774 fertiggestellt. Er verfasste sie also im Grunde in noch kürzerer Zeit, als dies der junge Montesquieu - dessen Lettres persanes sind ja ebenfalls ein Jugendstück - geschafft hatte. Aber Cadalso hatte ja auch mancherlei Vorbilder, darunter jenes des illustren Franzosen selbst.

Die weitere Veröffentlichungsgeschichte ist rasch erzählt: Das abgeschlossene Werk reichte José Cadalso im Oktober 1774 beim Consejo de Castilla in der Zensurbehörde ein, um die Druckgenehmigung zu erhalten. Er war freilich skeptisch, und seine Skepsis sollte sich bewahrheiten, machte man ihm doch zwar Hoffnungen, ließ ihn dann aber jahrelang warten, bevor es zu einer endgültigen Ablehnung kam. So wurden anders als die Lettres persanes, die ja - wie Sie sich erinnern - anonym im Ausland gedruckt wurden, die Cartas marruecas nicht mehr zu Lebzeiten des Autors veröffentlicht. Trotzdem zirkulierten damals bereits 
handschriftliche Abschriften - vier an der Zahl sind bis heute bekannt geworden innerhalb der spanischen Künstler- und Intellektuellenkreise. Erst im Februar 1789, also sieben Jahre nach seinem Tod und im Epochenjahr der Französischen Revolution, begannen die Cartas marruecas Cadalsos im Correo de Madrid sukzessive zu erscheinen, wobei einzelne Fragmente schon zuvor publiziert worden waren.

José Cadalsos Briefroman besteht aus insgesamt neunzig Briefen, denen eine „Introducción“ sowie andere paratextuelle Teile vorangestellt, nachgestellt oder andernorts einverleibt wurden. Cadalso spielte in seiner Einleitung, aber selbstverständlich auch schon im Paratext seines Titels auf evidente und bekannte ,ausländische“ Vorbilder an, deren Erfahrungen einer wechselseitig sich beleuchtenden Reflexion und Geschichte er für seine Marokkanischen Briefe übernahm und adaptierte. Diese aufklärerische Intertextualität ist für das Verständnis des gesamten Werkes unerlässlich.

In den Cartas marruecas ist die Zahl der Briefeschreiber gering. Sie beschränkt sich auf drei, von denen zwei Araber sind, während Nuño Núñez hingegen ein spanischer Christ ist. Im Unterschied zu Montesquieus Persern sind für die Spanier die Marokkaner keineswegs so weit entfernt wie die Perser für die Franzosen. Die Struktur und mehr noch die Anordnung der Briefe sind im Vergleich mit Montesquieus Lettres persanes weitaus weniger fixiert und festgelegt: Cadalso hatte offenkundig nicht die Absicht, die starke Systematisierung seines intertextuellen ,Vorgängers' zu übernehmen. Der spanische Aufklärer arbeitete dabei durchaus mit der historischen Wirklichkeit, indem er bei der Namensgebung von Gazel auf einen im Grunde gleichnamigen marokkanischen Botschafter anspielte, der einige Jahre zuvor Madrid für mehrere Monate besucht hatte und zu einem stadtbekannten Phänomen geworden war. Sie sehen also, dass schon bei dieser ersten Annäherung deutlich wird, dass es sich nicht einfach um eine bloße Imitation von Montesquieus Werk ein halbes Jahrhundert danach, sondern um einen sehr eigenständigen Versuch handelt. Dieser fand deshalb auch zu Recht an herausragender Stelle Aufnahme in die spanischen Literaturgeschichten. José Cadalso schrieb sich eigenständig in eine der Filiationen europäischer Aufklärung ein, wobei er - wie wir gleich sehen werden - nicht vergaß, sehr eigene Akzente zu setzen.

$\mathrm{Zu}$ den wichtigen intertextuellen Bezugstexten, auf welche die Forschungsliteratur zu den Cartas marruecas früh schon hinwies, gehört Oliver Goldsmiths The Citizen of the World von 1762. Es handelt sich dabei um die Briefe eines chinesischen Mandarins, der aus London nach China schreibt und aus dem britischen Königreich berichtet. Auch gegenüber diesem Bezugstext gibt es eine Reihe von Übereinstimmungen, die uns jedoch - abgesehen vom beherrschenden Thema des Weltbürgers, das den gebildeten Kosmopoliten Cadalso interessieren musste nicht näher zu interessieren brauchen. Denn dass Cadalso als ein früh schon mit 
unterschiedlichen europäischen Ländern und Sprachen vertrauter Mensch sich von Beginn an selbst auch als Weltbürger, als „Ciudadano del universo“ begriff, ist sehr naheliegend. Und in der Tat war er ja auch ein spanischer Bewohner jener République des Lettres, die sich im 18. Jahrhundert als intertextualisierendes Strukturmerkmal und grundlegende Kommunikationsbedingung in Europa herausgebildet hatte.

Freilich darf man in diesem europäischen Zusammenhang sehr wohl hinzufügen, dass Cadalso dies aus der Position Spaniens als Vertreter eines längst marginal gewordenen Landes tun musste, dem man vor allem in Frankreich keinerlei aufklärerische Impulse zuschrieb. Denn Spanien war zwar noch immer im Besitz des größten Kolonialreiches einer europäischen Macht, winnerhalb Europas aber längst von nur mehr marginaler Bedeutung und gehörte nicht zu jener ,petite Europe“, in der - wie wir sahen - Pierre Chaunu die eigentlichen dynamischen Kräfte Europas sich bündeln sah. Überdies war Spanien für Frankreich ein kolonialer Rivale, dessen Einfluss es in Europa zu begrenzen galt.

José Cadalso entwickelte freilich seinen spanischen Briefroman so, dass sich eine Vielzahl von augenzwinkernd vorgetragenen Berührungspunkten mit seinen intertextuellen Bezugstexten und insbesondere mit Montesquieus vorbildgebendem Text ergaben. Der marokkanische Briefeschreiber Gazel berichtet so im achtzigsten Brief an seinen Lehrer und Meister zuhause, an Ben-Beley in Marokko, aus einer Perspektive und aus einem Selbstverständnis, die sich sehr wohl mit der Entwicklung von Usbek in Paris in Verbindung bringen ließen. Die nachfolgend angeführte Passage wirft ein Licht auf die Dimensionen des Austauschs zwischen den Angehörigen verschiedener europäischer Staaten und Kulturen - freilich bezogen allein auf jene gesellschaftliche Gruppe oder genauer: Elite, der diese Beziehungen auch möglich und zugänglich waren. Im Folgenden also ein Auszug aus Brief Nummer 80, von Gazel an Ben-Beley:

\footnotetext{
Vor wenigen Tagen war ich bei einem exquisiten Scherz zugegen, den mit Nuño mehrere seiner ausländischen Freunde veranstalteten; freilich nicht von jenen, die zur Schande ihres jeweiligen Vaterlandes in der Welt herumlungern und voll der Laster all jener Länder sind, durch die sie in Europa gelaufen sind, und die mit sich die Gesamtheit all dieser Übel in diese Ecke der Welt schleppen, sondern vielmehr von jenen anderen, welche das Gute aller Länder nachzuahmen und wertzuschätzen versuchen und daher sehr gerne in allen aufgenommen werden. Mit einigen von diesen, die in Madrid wohnen, steht Nuño in Verbindung, und er liebt sie wie seine Landsleute, denn als solche erscheinen ihm alle guten Menschen in der Welt, so dass er ihnen gegenüber ein wahrhaftiger Kosmopolit ist, mit anderen Worten: ein Weltbürger. ${ }^{34}$
}

34 Cadalso, José: Cartas marruecas. Madrid: En la imprenta de Sancha 1793 S. 191 f. 
Auch hier stoßen wir also wieder auf das Idealbild des „citoyen de l'univers“, des Weltbürgers und Kosmopoliten, ${ }^{35}$ der in einer für das 18. Jahrhundert nicht weniger typischen Weise wiederum mit dem Begriff der „virtud“, der „vertu“ also, verknüpft wird, der wiederum einen der Schlüsselbegriffe des europäischen wie amerikanischen Aufklärungszeitalters schlechthin darstellt. Freilich sehen wir zugleich, dass der Kosmopolit in der Rede des in Madrid lebenden Marokkaners erstaunlicherweise ein die verschiedenen Länder Europas kennender Geist ist. Mit anderen Worten: Von Außereuropa ist in dieser Passage überraschenderweise nicht die Rede, obwohl Gazel doch gerade diesen Typus von Weltbürger, den er selbst auch darstellt, im Kopf gehabt haben dürfte. Doch vielleicht dachte José Cadalso zu sehr an seine eigenen Erfahrungen als junger Mann, die er hier niederschrieb, und weniger an die Tatsache, dass sich die Welt dieser Weltbürger nicht auf Europa beschränken konnte. Und wie sehr der Handel Verbindungen mit anderen Kontinenten schuf, wusste der spanische Schriftsteller aus dem Leben seines eigenen Vaters.

Doch kehren wir nochmals zur Struktur des gesamten Briefromans zurück! Von den insgesamt neunzig Briefen stammen sechsundsechzig Briefe von Gazel und richten sich an Ben-Beley; dazu kommen acht Briefe von Ben-Beley an Gazel sowie drei Briefe, die Nuño jeweils von Gazel und von Ben-Beley erhält, wobei er wiederum vier Briefe an Ben-Beley und sechs Briefe an Gazel schickt. Gleichwohl bildet Nuño einen zentralen und aktiven Punkt innerhalb dieser Korrespondenz. Zudem ist Nuño nicht zuletzt und vor allem der Führer Gazels durch die ihm zunächst wenig vertraute spanische, abendländische und christliche europäische Welt, die er aus der ,erfundenen“ marokkanischen Perspektive erblickt. Manches mag dabei dem Blick des jungen Cadalso geschuldet sein, als er als junger Mann wieder nach Spanien kam und sich im Seminario de Nobles erst einmal an die spanische Hauptstadt mit ihrem turbulenten Leben gewöhnen musste.

Die Cartas marruecas beinhalten eine klare Perspektivierung der spanischen Geschichte, als deren epochale Grundeinheiten die „Reyes Católicos“, die „Austrias“ sowie die „Borbones“ und damit die in Spanien regierenden Herrscherhäuser vorgeführt werden. Die Geschichte der Herrscher tritt damit als sinnstiftende Einheit in die sich in der Folge abspielenden und dargestellten Ereignisse wie ein ordnendes und lineares Prinzip ein. Repräsentiert diese dynastische Sichtweise von Geschichte ein modernes Geschichtsverständnis? Jedenfalls spielt sie gerade auch in der Bewertung der Rolle Spaniens als Kolonialmacht in Übersee eine wichtige Rolle.

35 Vgl. hierzu Kleingeld, Pauline: Six Varieties of Cosmopolitanism in Late EighteenthCentruy Germany. In: Journal of the History of Ideas (Baltimore) LX, 3 (July 1999), S. 505-524. 
Denn in den Cartas marruecas treten ein Verständnis und eine Sichtweise ans Tageslicht, die in deutlichem Kontrast zu jener Bewertung des spanischen Kolonialismus stehen, die wir anhand verschiedener hispanoamerikanischer wie europäischer Texte bereits kennengelernt haben. José Cadalso war sich dieser gesamteuropäischen wie hispanoamerikanischen Kritik am spanischen Kolonialismus sehr wohl bewusst, wie der Beginn der folgenden Passage verdeutlichen mag. Nur zu gut kannte er die Argumente, die gegenüber dem spanischen Kolonialreich und dessen Aufrechterhaltung gewöhnlich ins Feld geführt wurden. Doch stand er treu zum Königshaus und dessen Ansprüchen auf das weitgespannte Kolonialreich, das sich Spanien vor allem in Amerika erobert hatte.

Aus diesem Grunde ließ er dieser Passage dann in nicht weniger als einundzwanzig Punkten eine umfangreiche Verteidigung der spanischen Conquista und insbesondere des Hernán Cortés folgen, der im Übrigen auch an anderer Stelle zum Idealbild des großen Spaniers, ja zu einem der größten Spanier, die dieses Land je hervorgebracht habe, stilisiert wird. Hören wir nun aber den Brief von Gazel an Ben-Beley über die Frage nach der Situation Amerikas:

Ich habe gerade etwas von dem gelesen, was von den nicht-spanischen Europäern über die Eroberung Amerikas geschrieben wurde.

Wenn man auf der Seite der Spanier nichts hört als Religion, Heldentum, Vasallentum und andere des Respekts würdige Begriffe, so ertönt auf der Seite der Ausländer nichts als Habsucht, Tyrannei, Perfidie und andere nicht weniger grässliche Dinge. Ich konnte nicht anders, als dies meinem Freunde Nuño mitzuteilen, welcher mir sagte, dass dies ein der feinen Erörterung, gerechter Kritik und reifer Reflexion höchst würdiger Gegenstand sei; aber dass ich unter alledem und unter Bewahrung meines Rechtes darauf, mir davon einen Begriff zu machen, der mir fürderhin am gerechtesten erschiene, fürs Erste nur darüber nachdächte, dass die Völker, die so sehr ihre Stimme gegen die Grausamkeit der Spanier in Amerika erheben, genau dieselben sind, die an die Küsten von Afrika fahren, um vernunftbegabte Tiere beiderlei Geschlechts ihren Eltern, Brüdern, Freunden und siegreichen Kriegern abzukaufen, und dies ohne mehr Recht als das von weißen Käufern und von schwarzen Verkauften; sie schiffen sie gleich Tieren ein; sie verschleppen sie nackt, an Hunger und an Durst leidend, über Tausende von Meilen; dann laden sie sie in Amerika aus; sie verkaufen sie auf öffentlichem Markte wie Vieh zum höchsten Preise als gesunde und robuste Burschen, und zu weit mehr noch die unglücklichen Frauen, die sich mit einer weiteren Frucht des Elends in sich finden; sie nehmen das Geld; sie nehmen es mit in ihre allermenschlichsten Länder, und mit dem Produkt dieses Verkaufes drucken sie Bücher, die voller eleganter Vorwürfe, rhetorischer Verwünschungen und beredter Anklagen gegen Hernán Cortés und all das sind, was er getan; und was hat er getan ${ }^{36}$

36 Cadalso, José: Cartas marruecas, S. $33 \mathrm{f}$. 
Diese rhetorisch höchst geschickten Anklagen von José Cadalso gegen Spaniens Rivalen in Europa, die Spaniens Kolonialreich und die Grausamkeiten der Spanier angriffen, um gleichzeitig aber an einem lukrativen Sklavenhandel zu verdienen, an dem sie sich schamlos bereicherten, offenbaren eine Sichtweise, welche die spanische Herrschaft über Amerika rechtfertigt und die anderen Mächte Europas bezichtigt, sich nur aus Neid gegen Spanien zu verbünden. José Cadalso stand nicht umsonst als Militär, der für sein Vaterland kämpfte, fest an der Seite seiner Nation.

Offenkundig versucht Cadalso, in dieser Passage gegen die gegen Spanien gerichtete „Leyenda negra“ zu argumentieren, die hauptsächlich von Briten und Franzosen ins Feld geführt worden war, um die Grausamkeiten der spanischen Eroberung Amerikas anzuprangern und gleichzeitig die eigenen unmenschlichen Taten zu vertuschen. Denn de facto war es ja nicht so, dass sich diese Mächte in ihrem kolonialistischen Wahn humaner verhalten hätten: Frankreich etwa optimierte die Ausbeutung schwarzer Sklaven noch bedeutend und machte SaintDomingue zur profitabelsten europäischen Kolonie weltweit. Spanien aber, das noch immer das größte Kolonialreich besaß, versuchte man als besonders grausam darzustellen, um damit besser von der eigenen kolonialen Praxis ablenken zu können.

An genau dieser Stelle kippt die aufklärerische Argumentation des Spaniers José Cadalso um in einen nationalen Stolz auf die Eroberungen, welche die Konquistadoren in Amerika mit gutem Recht vorangetrieben hätten. Cadalso vollzieht an derartigen Stellen einen Blickwechsel nicht nur gegenüber amerikanischen Positionen wie diejenigen von Francisco Javier Clavijero oder Fray Servando Teresa de Mier, sondern auch gegenüber dem europäischen Mainstream der Aufklärung, der in Spanien - wie wir sahen - den eigentlichen Feind des Menschengeschlechts ausgemacht zu haben schien. Die gegenseitigen Propagandamaschinen der europäischen Kolonialmächte liefen auch und gerade in der Aufklärungsepoche auf vollen Touren und versuchten, die eigene kolonialistische Barbarei im hellsten Licht der Zivilisation erscheinen zu lassen. Bei José Cadalso erleben wir einen scharf akzentuierten Blickwechsel, gewiss, der aber einmal mehr die kolonialen Verstrickungen nicht nur Spaniens, sondern auch der anderen kolonialen Mächte Europas ins Blickfeld rückt. Dass im aufklärerischen Licht die eigene Barbarei verdunkelt wird, gehört ohne jeden Zweifel zu der von uns bereits mehrfach angesprochenen (kolonialen) Dialektik der Aufklärung.

Lassen Sie mich nebenbei anmerken, dass man selbst heute noch bei spanischen Geschichtsschreibern bisweilen auf derartige Argumentationen treffen kann. Diese beschwören die Größe Spaniens und verweisen dabei zugleich - und dies ist zweifellos ein zutreffender Gesichtspunkt - auf die kolonialistischen Absichten vor allem der neuen Führungsmächte der Globalisierung im 18. Jahrhundert, also 
Frankreich und England, aber auch Holland, um deren wenig humane Taten offenzulegen. Ähnliche nationalistische Argumentationen und Sichtweisen des Kolonialismus sind gerade im englischsprachigen Raum von großer Bedeutung, ist letztlich der Stolz auf das eigene „Empire“ doch auch heute noch ungebrochen. Lassen Sie mich dem noch hinzufügen, dass all diese kolonialistischen Verbrechen europäischer Mächte bis heute nicht gesühnt sind und es noch nicht einmal Entschuldigungen gegenüber den Kolonisierten, gegenüber den Versklavten gegeben hat, sondern bestenfalls den Streit darüber, wer sich innerhalb seiner schrecklichen Barbarei noch vorgeblich ,humaner‘ oder weniger barbarisch verhalten habe. Wie schwer es den europäischen Ländern noch immer fällt, ihren eigenen Kolonialismus beziehungsweise das Profitieren von anderen kolonialen Mächten einzuräumen und sich dafür zu entschuldigen, zeigt die aktuelle, hauptsächlich von Bénédicte Savoy angestoßene und mit vielen privaten Verletzungen verbundene Restitutions-Debatte um die Rückgabe geraubter Kunstwerke in Berlin.

Doch kehren wir zurück ins Zeitalter der Aufklärung und zu José Cadalso sowie seinen Marokkanischen Briefen! Die sich an die oben zitierte Passage anschließende Verteidigung des Hernán Cortés in den genannten einundzwanzig Punkten hat sich, wie wir etwas flapsig sagen könnten, dann gewaschen: Denn in Cadalsos Argumentationen erfolgt ein Rundumschlag, der zeigen kann, wie die Kritik aus spanischer Sicht an der Kultivierung einer „Leyenda negra“ durch Nationen, die selbst am Kolonialismus bestens verdienen, in ihr Gegenteil insoweit umschlagen kann, als damit wiederum eine Verteidigung des eigenen Kolonialismus fundiert wird. Wichtig ist, hier vor allem zu erkennen, wie sehr die Auseinandersetzung mit Außereuropa den europäischen Aufklärungsdiskurs in letztlich fast unaufhebbare Widersprüche verwickelt. Dies ist es, was ich mit der kolonialen Dialektik der Aufklärung meine: eine aufklärerische Kritik, die rasch in ihr Gegenteil umschlägt und Folgen zeitigt, die konträr zu den ursprünglichen oder eigentlichen Zielen der Aufklärung sind.

Denn deutlich wird sehr wohl, dass die anderen europäischen Nationen wie Holland, Frankreich oder England an der „Leyenda negra“ vor allem deshalb interessiert waren, um im Schlagschatten dieses Topos und dieser berechtigten Kritik ihren eigenen Kolonialismus gleichsam ungeschehen zu machen und noch besser vorantreiben zu können. Es ist, als hätte es das eigene kolonialistische Verhalten, die Ausbeutung von Sklaven, die Ausbeutung ganzer Kontinente nie gegeben.

Natürlich gilt dies gerade auch für die großen Kolonialismuskritiker Voltaire (den Cadalso sicherlich mitgemeint haben könnte) oder Raynal, die in der Tat zu den härtesten Angreifern insbesondere gegen den spanischen Kolonialismus zählten und dabei ganz heimlich unheimlich selbst hohe Gewinne aus ihren Investitionen in den Sklavenhandel einzustreichen verstanden. Das Argument von Nuño Núñez gegenüber einem aus Afrika stammenden Marokkaner, der Spanien natür- 
lich als ein expansives Land sehen muss, das dereinst die arabische Präsenz auf der Iberischen Halbinsel beendigte, das Argument also, man könne nicht den spanischen Kolonialismus angreifen und zugleich die Menschen Afrikas in die Sklaverei treiben und als Ware meistbringend verhökern, musste stechen: ebenso bei einem ,Afrikaner‘ wie bei einem Spanier, der diese Marokkanischen Briefe zu Gesicht bekommt.

Man könnte in diesem Zusammenhang durchaus von einem Argument sprechen, das zum einen autolegitimatorisch ist und zum anderen so ziemlich alles im Namen der eigenen partikularen Werte wie Ehre, Tapferkeit oder Vasallentum rechtfertigt. Ich widerstehe der Versuchung nicht, Ihnen doch zumindest einen kleinen Ausschnitt aus diesem Rechtfertigungs-Diskurs vorzuführen und zwar an einer Stelle, an der es um eine berühmte weibliche Figur geht, jene der „Malinche“ nämlich. Doch sehen Sie selbst etwa den fünften von insgesamt einundzwanzig Punkten:

$5^{\circ}$ Aus derselben menschlichen Schwäche weiß Cortés im Sinne seiner Absichten Vorteil zu ziehen. Eine adelige Indianerin, an welcher er leidenschaftlich Gefallen gefunden, dient ihm als zweite Dolmetscherin, und sie ist bei der Expedition von höchstem Nutzen: Sie ist die erste Frau, die einem Heere nicht geschadet, und ein bemerkenswertes Beispiel dafür, wie nützlich das schöne Geschlecht sein kann, solange es seine naturgemäße Subtilität auf löbliche und große Ziele richtet. ${ }^{37}$

Diese Passage - und übrigens auch ihr grotesker Kommentar in der Fußnote des spanischen Herausgebers meiner Ausgabe - mag belegen, dass die Frage der Geschlechtlichkeit sehr wohl mit der kolonialen Abhängigkeit in Verbindung zu bringen ist. ${ }^{38}$ In der mexikanischen Geschichte galt die Malinche als die indigene Verräterin schlechthin, half sie doch Hernán Cortés bei der Niederwerfung der Azteken von Tenochtitlán. Sie war die Dolmetscherein, die „lengua“ des Eroberers, aber auch eine gute Ratgeberin des spanischen Konquistadoren. Der männliche Blick auf die Frau ist oftmals ein kolonialistischer Blick, der die Frau bestenfalls zur Erreichung eines Zwecks nutzen will und damit kolonisiert. Wir könnten diese Thematik noch anhand weiterer Beispiele entwickeln, doch soll dies einer Vorlesung vorbehalten bleiben, die sich der Erfindung wie der Entdeckung Amerikas widmen wird.

Aber ich möchte Sie nicht nur vertrösten, sondern Ihnen auch zwei Punkte in Erinnerung rufen! Erstens die Tatsache, dass in der Tat die Präsenz Amerikas in der Aufklärungsliteratur wie in den Schriften des 18. Jahrhunderts allgegenwärtig ist, auch wenn man sich dieser Tatsache nicht immer bewusst sein muss. Und

37 Cadalso, José: Cartas marruecas, S. 35.

38 Vgl. hierzu Hölz, Karl: Das Fremde, das Eigene, das Andere. Die Inszenierung kultureller und geschlechtlicher Identität in Lateinamerika. Berlin: Erich Schmidt Verlag 1998. 
zweitens die Anmerkung, dass das argumentative Gerüst der Aufklärung in dem Augenblick, in dem die überseeische und koloniale Dimension hinzutritt, erheblich ins Wanken gerät und sich Widerspruch auf Widerspruch türmt. Wir hatten dies in unserer Vorlesung zum einen am Blick der Europäer auf die nicht-europäische Welt und dann in aller Deutlichkeit erneut in der Anwendung der europäisch abendländischen Prinzipien auf die europäische Aufklärung selbst durch nicht-europäische Autoren gesehen. Gerade die Berliner Debatte um die Neue Welt war im Kontext des Disputs, der seit Beginn des 16. Jahrhunderts transatlantisch um Amerika entbrannt war, in allen Einzelheiten und Konsequenzen diskutiert worden.

Denn in der Tat sind die Begrifflichkeiten der europäischen Aufklärung unhinterfragt an den Interessen Europas ausgerichtet und keineswegs an jenen universalen Prinzipien, die ständig den Diskurs der europäischen Aufklärung prägen. In diese Wunde hat die Aufklärung in Amerika schmerzhaft ihren Finger gelegt, was in Europa freilich gerne vergessen wurde. Europa brauchte lange, um den Diskurs der Aufklärung auch auf sich selbst anzuwenden und ihn auch auf sein asymmetrische Verhältnis zu außereuropäischen Teilen der Welt zu beziehen. Die „utilidad del bello sexo“, die Nützlichkeit des schönen Geschlechts, ist in den $M a$ rokkanischen Briefen des José Cadalso in ironischer Brechung nur eine zusätzliche Dimension dieser Widersprüche und Abhängigkeiten, in welche sich die Aufklärung in Europa verstrickte.

Diese Verstrickungen beziehen sich gerade auch auf die wechselseitigen Vorwürfe der Grausamkeit und Unmenschlichkeit, welche die europäischen Nationen stets auf die jeweils anderen zu projizieren pflegten und ihre Vorwürfe dabei im Gewand aufklärerischer Kritik vortrugen. Diese widerspruchsvolle Dialektik der aufgeklärten Kritik ist bis heute nicht vorüber: Wir stecken vielmehr mitten drin! Denn die furchtbaren und beispiellosen Verbrechen, die im Namen Deutschlands etwa während des sogenannten ,Dritten Reiches` verübt wurden, all die barbarischen und millionenfachen Massenmorde, die nie aus der Geschichte Deutschlands zu tilgen sein werden, haben den anderen aufgeklärten Nationen nicht zuletzt auch dazu gedient, ihre eigenen Verbrechen, ihren eigenen Antisemitismus, ihren eigenen Rassismus geflissentlich zu übersehen, um auf diese Weise alle Schuldkomplexe zu ,bewältigen' und sich reinzuwaschen. Die Literaturen der Welt freilich sind in ihrer Gesamtheit ein untrügliches Medium, das anders als eine nationale Geschichtsschreibung zu disziplinieren ist. So ist ein Roman der französischen Schriftstellerin Cécile Wajsbrot, der sich mit den polnischen Pogromen an Juden nach 1945 beschäftigt, niemals ins Polnische übersetzt worden. Doch die Zeit wird auch hier kommen, um Dinge anzusprechen, welche die nationale oder nationalistische Historiographie noch geflissentlich übersieht. Die Literaturen der Welt bewahren nicht allein das polylogische Gedächtnis dieser Geschichte auf, sondern ermöglichen es 
vor allem, die Vergangenheit prospektiv für die Zukunft fernab aller Projektionen und Vertuschungen zu nutzen.

Die probate Vorgehensweise, mit dem Verweis auf die Schuld und die Verbrechen anderer die eigene Schuld zu tilgen und die Größe der eigenen Nation herauszustreichen, ist ein Verfahren, das uns der spanische Aufklärer José Cadalso gegen seinen Willen in seinen Cartas marruecas in aller wünschenswerten Deutlichkeit vor Augen führt. Auch in diesem für Sie vielleicht etwas unerwarteten Sinne sind wir noch immer Kinder der Aufklärung und zugleich Kinder einer Dialektik der Aufklärung, welche bereits innerhalb der Aufklärung selbst - innerhalb einer Aufklärung zwischen zwei Welten - transatlantisch freigelegt worden ist. Wir müssen uns nur dem von Europa weitgehend ausgeschlossenen Teil der Aufklärung gegenüber öffnen. Doch in der Rede von einer Dialektik der Aufklärung steckt noch im letzten Teilchen unserer kritischen Reflexionen und Argumente die gefährliche Möglichkeit einer Instrumentalisierung von Vernunft, die gegen-vernünftig und irrational selbstlegitimatorisch ist. Davor gilt es sich auch heute noch zu schützen!

Bei unserer Analyse von José Cadalsos Cartas marruecas habe ich einmal nicht mit der Analyse des Paratextes begonnen, sondern bin sogleich in medias res gegangen. Doch möchte ich Ihnen gegen Ende unseres kurzen Durchgangs doch noch einen Blick auf die „Introducción“ gewähren. Sie beginnt mit dem Verweis auf Cervantes' Don Quijote, um dann selbst eine ähnlich gelagerte Herausgeberfiktion - das Auffinden des Manuskripts eines Freundes und dessen selbstlose Veröffentlichung - natürlich fiktional vorzutäuschen, im Grunde ganz so, wie es auch Jean-Jacques Rousseau mit den Briefen seines Briefromans Julie ou la Nouvelle Héloïse tat.

Nun, Sie wissen ja, dass sich ein derartiges Verfahren nicht nur bei Cervantes oder Rousseau findet, sondern auch in Montesquieus Lettres persanes und somit in einer doppelten literarischen Filiation, in welche sich die Cartas marruecas einschreiben. Daher wird in der Einleitung auch gleich noch diese Herausgeberfiktion wieder dekonstruiert, in ihrer Mechanik also vorgeführt, ohne doch ganz einfach destruiert zu werden. So bleibt dieses seltsame Oszillieren zwischen Herausgeberfiktion und Autorenanspruch bis in den letzten Abschnitt der Einleitung aufrechterhalten, wo noch ein letztes Mal die Bedeutung des gesamten Textes angesichts der zu erwartenden Kritik aus Spanien unterstrichen werden soll. Dabei steht erneut die Prinzipientreue der spanischen Aufklärung im Vordergrund - eine Ausrichtung an Vorstellungen der Aufklärung wie etwa der „hombría de bien“, gleichsam des aufrichtig gemeinten Gutmenschentums, der „virtud“, der „razón“ oder der „imparcialidad“, die in dieser Passage noch einmal deutlich hervortreten: 
Wenn ich in der Konsequenz dessen als armer Herausgeber dieser Kritik mich in gleich welchem Hause einer dieser beiden Orden präsentiere, so können sie mir, auch wenn sie mich mit einigem guten Willen aufnehmen, es doch nicht abnehmen, dass ich mir gemäß aller Umstände sage: dass sie in diesem selben Augenblick untereinander sagen: Dieser Mann ist ein schlechter Spanier; oder aber: Dieser Mensch ist ein Barbar. Aber meine Eigenliebe wird mich trösten (wie dies in vielen Fällen bei anderen geschieht), und so werde ich mir selbst sagen: Ich bin nicht mehr als ein gutmeinender Mensch, der ein Papier zur Welt gebracht, welches mir sehr unparteiisch erschien, ein Papier über den empfindlichsten Gegenstand, den es auf der Welt gibt, nämlich die Kritik einer Nation. ${ }^{39}$

Noch einmal wird in dieser Passage das Pathos des Aufklärers beschworen, der sich gegen die Anfeindungen seiner Gesellschaft und seiner Zeitgenossen zur Wehr setzen muss. Der zentrale Begriff der Aufklärung, die Kritik, wird hier mehrfach als verpflichtendes Ideal und als Praxis genannt, die den aufklärerischen „hombre de bien“ von all seinen Widersachern unterscheidet. Darüber hinaus sind es die zentralen Werte und Begriffe der Aufklärung, die vom - wie wir etwas avant la lettre sagen können - ,Intellektuellen' innerhalb einer aufkommenden bürgerlichen Gesellschaft verlangen, sich gegen den Mainstream, gegen die vorherrschende Meinung, gegen einen blinden Nationalismus und gegen die Ansichten der Mehrheit zu stellen. Dass es Cadalso freilich durchaus verstand, die Ehre Spaniens zu verteidigen, haben wir am Beispiel der Verteidigung von Hernán Cortés gesehen.

Es besteht keinerlei Zweifel daran, dass José Cadalso - wie so viele Aufklärer vor ihm und nach ihm - diese Position einer ,verfolgten Tugend' für sich reklamiert. Das Bild des kritischen Intellektuellen, wie es im Grunde in der Aufklärung bereits angelegt und in der Figur Voltaires vorgelebt wurde, ist in Cadalsos Cartas marruecas sehr wohl zu finden, ist es doch dieser kritische Intellektuelle, dem die Aufgabe anvertraut wird, das Volk zu leiten und natürlich auch aus dessen Ignoranz und Unmündigkeit herauszuführen. Zugleich aber muss sich dieser „filósofo“, dieser ,Intellektuelle‘, auf einer anderen Stufe, auf einer anderen Ebene als das Volk ansiedeln. Cadalso weiß sich hier sehr wohl im Verbund mit anderen kritischen Philosophen, „philosophes“ und „filósofos“, die letztlich einen ähnlichen gesellschaftlichen Führungsanspruch in ihren Ländern erhoben. Von dieser Position des Intellektuellen avant la lettre aus wird sein gesamtes Handeln, gerade auch sein sprachliches Handeln, verankert und begründet.

Aufschlussreich ist zweifellos der Hinweis in den Cartas marruecas, die Europäer seien insgesamt mächtig stolz auf ihr 18. Jahrhundert, doch solle man sich vom Schein nicht täuschen lassen: Denn es gebe zwar viel Aufklärung, deren Schein jedoch trüge. Eben dies wird wiederum zum Ausgangspunkt für die neu

39 Cadalso, José: Cartas marruecas, S. viii. 
einsetzende Kritik des „hombre de bien“. Denn Kritik ist, wie wir schon mehrfach sahen, das zentrale Wort und Versprechen der Aufklärung. Doch wie gewaltig die Zonen sind, die keiner Kritik oder nur einer ganz bestimmten selbstlegitimierenden Kritik offenstehen, haben wir gerade am Beispiel des Verhältnisses zwischen Europa und dem kolonisierten ,Rest“ der Welt gesehen.

Lassen Sie mich an dieser Stelle der Vorlesung aus einer vielleicht überraschenden Perspektive auf die Frage nach den Intellektuellen zurückkommen, deren Begriff freilich im 18. Jahrhundert noch nicht im modernen Sinne zur Verfügung stand. Nun sind wir im Verlauf unserer Vorlesung immer wieder auf Mitglieder des Klerus als Träger der Aufklärung - etwa auf einen der berühmten „Abbés“, den Abbé Raynal oder den Kirchenmann de Pauw, auf den Jesuiten Clavijero oder ebenfalls in Neuspanien auf den Dominikaner Fray Servando Teresa de Mier - aufmerksam geworden oder haben zumindest bemerkt, wie sehr bestimmte Autoren wie etwa Cadalso, aber auch Voltaire und viele andere, von der hervorragenden Ausbildung insbesondere durch Jesuiten geprägt wurden. Die „philosophes“ des 18. Jahrhunderts besitzen eine auf den zweiten Blick keineswegs zufällige Beziehung zum Klerus, gehören diesem entweder an oder aber übernehmen Funktionen, Rollen und Selbstverständnis dieser minoritären Gruppe innerhalb der Gesellschaft des Siècle des Lumières, um diese Funktionen und Rollen in der Folge dann zu entsakralisieren.

Das ist mit Blick auf die weitere gesellschaftliche Entwicklung nach dem Aufklärungszeitalter höchst aufschlussreich. In gewisser Weise - und dies zeigen auch etwa die späteren Überlegungen eines Antonio Gramsci - sind die französischen (und anderen) Philosophen und in ihrer Folge die Intellektuellen die Erben des Priestertums in einer dann zunehmend entsakralisierten, profanen bürgerlichen Gesellschaft. Dies erklärt zum einen die besondere Bedeutung der „Abbés“ oder der „Frayles“, zum anderen aber auch manche Verhaltensweise von Intellektuellen heute, die ohne diese Vorgeschichte schlechterdings nicht verstanden werden könnten. Denn sie sind in vielerlei Hinsicht noch immer die entsakralisierten Kleriker einer nicht länger gottgläubigen Gesellschaft - Hohepriester eines Denkens, das für sich eine Führungs- und Leitungsrolle beansprucht.

Es ist daher interessant, einmal die Überlegungen nachzuprüfen, die etwa in der französischen Encyclopédie nach der Jahrhundertmitte zum Thema „Priester“ angestellt wurden. Der entsprechende Artikel wurde von keinem Geringeren als Paul-Henri Thiry, Baron d'Holbach verfasst, der 1723 in Edesheim bei Landau geboren wurde und als großer französischer Aufklärungsphilosoph zu Beginn des Jahres der Französischen Revolution in Paris verstarb. Schauen wir uns einen Auszug aus diesem Artikel einmal etwas genauer an: 
Es ist angenehm, über seinesgleichen zu herrschen; die Priester verstanden die hohe Meinung, die sie im Geist ihrer Mitbürger von sich erzeugt hatten, zu ihrem Vorteil auszunutzen; sie behaupteten, dass die Götter sich ihnen offenbarten; sie gaben ihre Ratschläge bekannt; sie lehrten Dogmen; sie schrieben vor, was man glauben und was man verwerfen sollte; sie legten fest, was dem göttlichen Wesen gefiel oder missfiel; sie verkündeten Orakel; sie sagten dem unruhigen und wissbegierigen Menschen die Zukunft voraus, sie ließen ihn aus Furcht vor den Strafen zittern, mit denen die empörten Götter den Vermessenen drohten, die an ihrer Mission zu zweifeln oder ihre Lehre zu diskutieren wagten. [...]

Die schreckliche Inquisition liefert in den Ländern, wo sie eingeführt ist, häufig Beispiele für Menschenopfer, die an Barbarei denen der mexikanischen Priester keineswegs nachstehen. Anders liegen die Dinge in den vom Licht der Vernunft und der Philosophie aufgeklärten Landstrichen, wo der Priester niemals vergisst, dass auch er Mensch, Untertan und Staatsbürger ist. ${ }^{40}$

In dieser Passage aus dem Artikel der Encyclopédie wird deutlich, welche Bedeutung den Priestern sozusagen transkulturell - also quer durch die verschiedenen Kulturen hindurch - beigemessen wird. Die Priester werden einerseits aus ihrer sozialen Rolle heraus definiert, andererseits aus ihrem Sozialverhalten, das sich dadurch auszeichnet, dass sie sich Machtpositionen innerhalb des Staates und jenseits von ihm zu erobern trachten und auch stets zu erobern schon immer getrachtet hätten. Damit kommt Priestern eine Leitfunktion innerhalb der kulturellen Spannungsverhältnisse und innerhalb der unterschiedlichsten Gesellschaften und Kulturen zu. Auf diese Weise werden sie einerseits zu Männern des Wissens, andererseits aber auch zu Herren über das Wissen, die nicht nur den Zugang zum Wissen kontrollieren, sondern auch Strafen verhängen und den rechtmäßigen Weg, das Dogma, von dem es kein Abweichen gibt, zu verkündigen berufen sind.

Als Extremform dieser Herrschaft der Priester, die für sich eine besondere Aura beanspruchen, darf die Inquisition gelten, die wiederum in erster Linie auf Spanien zielt, in zweiter aber auch auf andere Länder, in denen sie wirksam war. Folgen wir der Schlusspassage des obigen Zitats, dann kann das Licht der Vernunft und der Philosophie die Einstellung der Angehörigen des Klerus selbst insoweit verändern, als diese sich nunmehr nicht länger allein von jener gesellschaftlichen Formation her begreifen und selbst verstehen, die man als Gemeinschaft der Kirche oder auch als Religion bezeichnet. Es ist also keineswegs zwingend davon auszugehen, dass es einen grundsätzlichen Gegensatz zwischen Priestern und Philoso-

40 D’Holbach, Paul Henri Thiry Baron: Artikel „Prêtres“. In: Diderot, Denis / D’Alembert, JeanBaptiste le Rond (Hg.): Encyclopédie, ou Dictionnaire raisonné des sciences, des arts et des métiers, 1re éd. Dix-sept volumes plus neuf volumes de planches. Paris 1751, Bd. 13, S. 340-343, hier S. 341 . 
phen, zwischen Kirchenmännern und Intellektuellen gibt, wie er später ins 18. Jahrhundert zurückprojiziert wurde.

Entscheidend vielmehr ist, dass wir in diesem Bereich die gesellschaftlich akkreditierten Kontinuitäten sehen. Die Tonsur und damit eine berufliche Karriere innerhalb des Klerus sagte im 18. Jahrhundert wenig aus über den wirklichen Glauben des jeweiligen Menschen. So werden wir gegen Ende unseres Durchgangs durch das 18. Jahrhundert auf einen Menschen stoßen, dessen Name keineswegs die Assoziationen von Gläubigkeit und Religion erweckt, es sei denn, man würde darunter die Verehrung der Frauen verstehen. 